Skidmore College

Creative Matter

Sociology Senior Seminar Papers

Sociology

$5-2019$

\title{
Searching for Silver Linings in Foreign Grounds: Children of Immigrants and Their Quest to Post-Secondary Education
}

Ashley Mejia

Skidmore College, amejia1@skidmore.edu

Follow this and additional works at: https://creativematter.skidmore.edu/socio_stu_stu_schol

Part of the Migration Studies Commons, and the Secondary Education Commons

\section{Recommended Citation}

Mejia, Ashley, "Searching for Silver Linings in Foreign Grounds: Children of Immigrants and Their Quest to Post-Secondary Education" (2019). Sociology Senior Seminar Papers. 33.

https://creativematter.skidmore.edu/socio_stu_stu_schol/33

This Thesis is brought to you for free and open access by the Sociology at Creative Matter. It has been accepted for inclusion in Sociology Senior Seminar Papers by an authorized administrator of Creative Matter. For more information, please contact dseiler@skidmore.edu. 
Searching for Silver Linings in Foreign Grounds: Children of Immigrants and Their Quest to Post-Secondary Education*

\author{
Ashley Mejia
}

Skidmore College

Word Count $=7,752$

*Please direct all correspondence to Ashley Mejia by email at amejia1@skidmore.edu and mail at Skidmore College, 815 North Broadway, Saratoga Springs, NY 12866. The author wishes to acknowledge the generous support of Andrew Lindner, Catherine Berheide, and her seminar colleagues. 
Searching for Silver Linings in Foreign Grounds: Children of Immigrants and Educational

\title{
Attainment
}

\begin{abstract}
In recent years there has been an increase of immigrants in the United States and upward mobility has become extremely challenging through secondary education. Higher education is deemed to be one of the most important factors associated with upward mobility and economic stability. While the achievement gap continues to widen, children of immigrants continue to struggle to assimilate and in gaining access to the white middle-class mainstream. Ultimately, the snowball effect of intergenerational low socioeconomic status rolls over on to the disadvantage immigrant children in the new generation. I propose that children of U.S. born parents have a greater educational attainment than children of immigrants. Using the 2016 General Social Survey $(\mathrm{N}=1,899)$ this study investigates the relationship between parents' place of birth and respondents' educational attainment. At the bivariate level, children of immigrants attain fewer years of school. However, this relationship appears to be largely mediated by parental education. After controlling for sex, race, and perceived income at age 16, it was found that respondents' educational attainment is not greatly affected by parents' birthplace but by parents' years of education completed. Guided by insights from Bourdieu's theory of Habitus and straight-line assimilation theory, the findings show that education plays a major role in patterns related to the assimilation theory and the acquisition of the habitus. Respondents' educational attainment is fundamentally driven by the systematic structures in society concerning parent's education and status.
\end{abstract}




\section{INTRODUCTION}

The expression, "the United States is like a melting pot," is not to be taken lightly. The United States is home to immigrants from many different parts of the world and today 40 million people living in the U.S. were born in another country. Since 1965, when U.S. immigration laws emphasized family reunification and skilled immigrants, the number of immigrants living in the U.S. has more than quadrupled (Bialik, López, and Radford 2018). Immigrants come into the United States expecting to improve their quality of life and attain economic stability. They bring with them important cultural traditions from their home country and integrate them in their daily lives. Many of these families cultivate an environment at home that emphasizes attaining a higher education, as education is deemed to be one of the fundamental groundworks of upward mobility. Although, this may seem like a reasonable and attainable plan for immigrant families, the process of assimilation is far more complicated than what we see on the surface. Most immigrants struggle with language barriers, cultural differences, racial profiling, and lack of resources and opportunities.

In the past 25 years, the number of undocumented immigrants in the United States has grown substantially, from an estimated 2.5 million 1987 to 11.1 million today (Passell 2006; Passel and Cohn 2010). The United States is the primary destinations for most families because they truly believe it is the land of the free. However, in most cases, immigrants are abruptly woken by the reality that is, there is hardly any upward mobility without education and there are rarely any opportunities for a higher education without the financial means.

A reoccurring theme in sociology is the process by which individuals acquire social and cultural capital and how diverse these forms of capital can be applied and manifested in their lives. Social and cultural capital emerges in early childhood and it is solely dependent on 
socioeconomic status which can result in education stratification. In other words, the more wealth and access to elite social spaces parents have the higher the chances are that their children will adapt to the institutional norms embedded in society. By utilizing social networks and economic resources children born into middle-class and upper-class families in the U.S. have the opportunity to gain access to elite schools, jobs, and unique experiences that can shape their educational pathway and life trajectory (Hirschman 2016). While being born in a lowsocioeconomic environment reduces the chances of the vulnerable population to progress in life and actively participate in the community, it implies that these environments have less cultural capital which means less opportunities for upward mobility. Assimilation has been identified as "a process of interpenetration and fusion in which persons and groups acquire the memories, sentiments, and attitudes of other persons and groups and, by sharing their experience and history, are incorporated with them in a common life" (Park and E.W. Burgess 1969; Alba and Nee 1997). With the influx of mass immigration, the demand for employment has increased along with the standards of employers and the changing economy. As a result, the "American" quality of life that second generation immigrants aim for requires a higher educational attainment which can be accomplished through the process of assimilation. However, the burden immigrant children encounter as they integrate into a new culture becomes a greater obstacle for them in the education field, which makes the process of assimilation and upward mobility an enduring longlasting hardship. The social problem of immigration and educational attainment then becomes an issue affecting millions of individuals financially and emotionally. The question I will explore is, how does parents' birthplace shape postsecondary/higher education attainment among the children of immigrants and non-immigrants?

Often times, immigrant parents and immigrant children have to assimilate and adapt to the American mainstream culture which, as a shortcoming, can lead to a loss in cultural values. 
In the processes of assimilation, the dominant group play a unique role in shaping the experiences of children of immigrants. In some cases, the prevailing group may welcome and embrace the minority groups into social cliques, clubs, and institutions resulting in children of immigrants adapting to the mainstream America and losing part of their culture. Which can ultimately lead to personal identity conflicts. In addition, children of immigrants that are not easily integrated or welcomed in their community may experience loss of self-confidence and can result in following a downward mobility path.

This research paper will extend on the literature by first understanding how oppression is systematically enforced through education in regard to tracking in schools and reinforced through social interactions. Institutional structures and agency work hand in hand to perpetually distort minorities' reality by keeping them below the poverty line. Competition among the upper, middle, and lower class is one of the frameworks institutions utilize to promote self-sufficiency, while also promoting division amongst the rich and the poor. Thus, pushing individuals born in the United States to work smarter, not harder. The theoretical significance of this research question extends on the concept of educational attainment and cultural development, which fundamentally is one of the first encounters members of a society are exposed to in their early childhood. Parents' birthplace, socioeconomic status, and educational attainment play important roles in the process of integration and upward-mobility. The 2016 General Social Survey data will assist this research paper in exploring the most current data on children of immigrants and educational attainment, it will further elaborate on previous research by analyzing the influx of immigration and educational opportunities in 2016. I hypothesize that children of native U.S. born parents have a greater educational attainment than children of immigrants. 


\section{LITERATURE REVIEW}

People naturally ask, "where are you from?” for most citizens they have a clear answer, yet, for many children of immigrants this answer can be very different, "I live in New York, but my mom is from Guatemala..." the question of ethnicity and racial identities lingers heavily over this simple question. Ethnic identity is situational and unique across immigrants and ethnicity is an important factor in major life decisions. Most individuals from different ethnic groups think about success differently, for example, an individual who grew up in a low socioeconomic neighborhood might think getting a GED is success while, individuals who grew up in high socioeconomic status believe attaining a bachelors or a master's degree is success. Most of these beliefs, stem from the cultural and social values individuals have acquired through experiences inside and outside of the classroom.

Previous research has shown a considerable amount of concern for the achievement gap in the tracking of education amongst Blacks and Latinos. In Keeping Track: How Schools Structure Inequality by Jeannie Oakes (2005), defines tracking as the process of dividing students amongst groups of similar characteristics. Tracking is not designed to influence or increase students' social or emotional growth; the sole purpose of tracking is to maximize an optimum level of instruction that yields efficiency. Meanwhile, this type of structure in schools stratifies black and Latinos by compartmentalizing them in lower ability tracks. The methods of tracking have had a negative effect on the self-esteem of "low-ability students" and limits their college options because when students are constantly grouped with low-performers, they will eventually view themselves as one of the low performers which results in a loss of motivation and confidence (Oakes, 2005). Furthermore, a lot of minority students experience racial bias, labels - deviant, trouble-maker, class clown - and discrimination early in their education which alienates and prevents them from 
attaining the cultural capital needed to gain the confidence to pursue a higher education (Hirschman 2016; Oakes 2005).

It is not surprising to find in the literature that perceived discrimination reduces immigrant youth's self-esteem. Racial bias in the face of assimilation lowers children of immigrants' overall educational expectations and academic motivations, which, as a result, hinders their academic performance (Potochnick 2014; 22). According to the segmented assimilation theory, the success of an immigrant's assimilation can be very different across immigrant groups because of factors such as, racial discrimination and racial bias (Gonzales 2011; Potochnick 2014; 25).

The vicious cycle of exclusion and adaptation intensifies the gap of class inequality in U.S. higher education. In previous studies they have documented the persistent effect of socioeconomic status in producing differences in access to postsecondary education. A National Education Longitudinal Survey coupled with a three nationally representative cohorts of seniors, after analyzing the data it was found that between 1982 and 1992, class disparities in access to more selective institutions widened more than those regarding attendance at two-year institutions. In addition, examined post-secondary education gaps changes in test scores over time by race/ethnicity in the study revealed that "...class based convergence and polarization of the test score distribution were most pronounced among whites" (Alon 2017; 745). Immigrant children are less likely to have the means to access paid tutoring and other resources, which could partially explain the big difference in test scores and attendance in school. Although, social trust is not specifically measured in this study, it is important to identify that trust is fundamentally rooted in children who are nurtured in a safe environment. Children of immigrants might not be able to fully trust the people in their new environment because of the harsh transition they have experienced and they also might even be afraid to ask for help. Whereas, white children born in the U.S. with educated parents, might not have a problem asking their teachers for help on future exams or asking 
their parents to pay for tutoring. As a result, children of immigrants can become isolated from their peers which leads them to acquiring less cultural capital. It was found that the probability of trusting strangers is higher among people with high levels of both education and life satisfaction than for their counterparts who have low educational level and are not satisfied with their life (Zanin 2016; 935). Which in this case would explain why many immigrant children and immigrant parents do not trust the education system or people in outside of their tight circle in general (Gonzales 2010; Zanin 2016).

Consequently, children of immigrants' struggle with assimilating because majority of their experiences consist of negative stereotypes that are projected on to them. The second generation of immigrants is better defined as undergoing a process of segmented assimilation by where outcomes vary across immigrant minorities and where rapid integration and acceptance into the American mainstream culture represent different possible alternatives. In light of Bourdieu's cultural capital theory, and segmented-line assimilation theory, the individual's placement of higher education depends on socioeconomic origins and shapes the economic outcomes of college graduates, essentially enforcing the maintained inequality by systematically stratifying students in specific educational levels (Torche 2011). Education stratification can be explained through Pierre Bourdieu's habitus and cultural capital theory.

Pierre Bourdieu's theoretical framework explains the social processes of education and assimilation, while borrowing insights from the straight-line assimilation theory, intergenerational mobility theory, and cultural capital theory (Tourche 2011; Potochnick 2014; Alba and Nee 1997). Bourdieu, (1997) has argued that while there are several forms of capitaleconomic, social, human, and cultural capital — cultural capital is considered to be the most valuable in the education field. Capital, which, in its objectified and internalized forms takes time to accumulate in the utmost structured manner, is one of the oldest, yet one of the most 
powerful institutionalized methods upholding social inequalities. Since, cultural capital is deemed to be the most appropriate form of capital to determine whether or not an individual will gain access to upward mobility it begs the question of how to determine the right cultural capital to use in specific spaces. Considering that cultural capital cannot be measured, parents' educational attainment serves as a proxy measure in this study.

Furthermore, most qualitative studies evaluate the process of educational attainment for immigrant children through Bourdieu's perspective. Bourdieu proposed that social reproduction, social class differences, cultural capital, and habitus begin in early childhood (Dumais 2005; Alba and Nee 1997). One might even insinuate that individuals have little to no control over their acquired capital since birth, which is why I expected to see a different outcome in educational attainment for children of immigrants because they might not have the social skills to help them advance in an environment where cultural capital is crucial for upward mobility like in the United States. In that case, the environment of where parents were brought up in can be a determinant of the type of cultural and social capital acquired. For instance, if the parent was born in a poor country that was not able to offer them the necessary resources needed to attain higher education then the parent would not be able to transmit the cultural and social capital learned through education.

Consequently, Gonzales (2010) adds that schools facilitate the development of aspirations rooted in the belief that immigrant children are a part of the community through the exchange of cultural capital and experiences. As children of immigrants exchange their cultural values in the environment their parents settled in, they could either be welcomed into their communities by assimilating and optimizing their shared experiences in schools or be isolated from their communities. In Gonzales qualitative study, he interviewed 150 students who migrated before the age of 12 to the United States. The respondents were questioned in different stages throughout 
their lives in the transition to adulthood. Most of the respondents felt that they did not have any access to education because they did not have access to counselors and some of the respondents simply did not trust the individuals in their school to help them. As high school counselors play an important role in getting college information Exploring educational attainment in light of parents' place of birth and socioeconomic status is a start to understanding cultural capital because the location of birth can determine the accessibility to education and wealth which can determine the different forms of knowledge acquired through cultural capital.

Which is why parents born in the U.S. that are part of the upper-class families possessing large amounts of cultural and economic capital have transmittable cultural capital they can share with their children which can help them and motivate them to get a higher education. Meanwhile, working-class and poor families born outside of the United States are not expected to be exposed to a great deal of social and cultural capital as they are in an environment trying to survive. Since social reproductions and class differences emerge in early childhood, immigrant children start off at a disadvantage at birth. The hours and the expected benefits of individuals' investment in their preferences in education develops human capital and determines available opportunities, which results in social class differences directly correlated to the habitus involving the internalization of social structure (Potochnick 2014; Dumais 2005). The habitus one acquires through educational attainment forms the way individuals perceive the world and this habitus serves as a guide in the individual's life. For instance, growing up in a family with a low socioeconomic status who have not gone to college eventually shapes the individual's mind into unconsciously internalizing the belief that school is not for them (Dumais 2005; Gonzales 2010).

Furthermore, emphasizing the segmented assimilation theory explains how secondgeneration immigrant children tend to adapt into the mainstream culture or can possibly go the other way of downward integration of immigrants' (Feliciano 2005). The relationship between 
class and engagement in child cultivation is a prominent effect of social inequality and educational attainment which entails that assimilating is by far one of the most important processes to set up the framework between engagement and cultivation (Lareau 2002; Feliciano 2005). In addition, quantitative research has emphasized the difference between non-white immigrant and white immigrants' path to assimilation. Arguing that families' strong ties to the ethnic community may insulate second-generation immigrants from negative outside influences (Raleigh and Grace 2010; Bourdieu 1990). The straight-line assimilation suggests that there is a straight pathway child of immigrants normally follow that allows them to fully assimilate into their community. Realistically, it is never easy for children of immigrants to assimilate they often end up following different pathways to assimilation which can be explained through the segmented assimilation theory.

The straight-line assimilation theory has been ridiculed and exhausted by many scholars and social scientists. Many have argued that the assimilation theory imposes ethnocentric and patronizing demands on minority people (Alba and Nee 1997; Feliciano and Lanuza 2017). Furthermore, existing literature emphasizes the race factor in post-secondary education. Upwardly mobile students of color in elite schools often encounter cultural norms and expectations that differ from their own, which increases the feelings of alienation and isolation from their families and friends back home while also feeling marginalized and excluded by their more privileged peers (Cox 2017, 50). These feelings of isolation are a result of education stratification in which shadow capital replaces the authentic forms of cultural and human capital (Cox 2017; Cipollone and Stich 2017).

When analyzing two forms of test preparation, researchers found that while black students were most likely to utilize private tutoring the impact of private tutoring was trivial for all racial/ethnic groups in the study. The levels of social capital and preparation for post- 
secondary education are put into motion long before one enters secondary school. The dominant group is rewarded by the education system. Since students with high socio-economic status and more social capital are precisely groomed for higher education since birth, they have the upper hand, while the lack of post-secondary preparation leaves the less dominant group struggling to gain status in a post-secondary educational environment (Cipollone and Stich 2017; Gonzales 2011). As a result, students make decisions based on their habitus and the range of cultural capital available to them, which develops from the interactions the student encounters in school, with their family, and their community (Benner, Boyle, and Sadler 2016; Hsin and Ortega 2018; Cipollone and Stich 2017). According to the segmented assimilation theory and the forms of acquiring the habitus I expect to see a difference in educational attainment amongst children of immigrants and of children who had parents born in the U.S because there is less accessibility to resources and social connections for children of immigrants.

\section{THEORETICAL FRAMEWORK}

The primary factors that directly lead to success in attaining a higher education are correlated with children's' socialization, socioeconomic status, resources, and social class. Bourdieu's notions of habitus and cultural capital have proved to be crucial for understanding how social class shapes individuals and their future pathways to a higher education; empirical studies find an overall positive association between socioeconomic status and parental involvement (Cherng and Ho 2018). Socioeconomic status can be explained as a combination of resources that include income, educational attainment, and job occupation. Bourdieu habitus theory is a critical component for this study as it pertains to the explanation of how individuals acquire their behaviors, taste, and aspirations through their socioeconomic status. The allocation of resources and economic capital is part of the habitus as it determines what kind of exposure different groups of people are able to navigate (1990). 
It is not surprising that socioeconomic status reflects in how parental involvement may or may not help immigrant children succeed. In most cases, children of immigrants with low socioeconomic status do not have the resources from their parents offered through human and cultural capital to help these children get into the elite social spaces hosted by higher education organizations (Benner, Boyle, and Sadler 2016). Organizational structures can function as tools for building - and embedding participants within—social networks with advantages and externalized economic capital (Cox 2017; Gonzales 2011). Instead, immigrant children with low socioeconomic parents are burdened with the task of doing chores and housework like taking care of their siblings and applying for jobs as opposed to focusing on their studies and other extra curriculums like the higher socioeconomic status children (Gonzales 2011; Dumais 2005; Potochnick 2014).

The theories driving this research are segmented assimilation theory and Bourdieu's cultural capital and habitus theory. The segmented assimilation theory suggests that different immigrant groups assimilate into different segments of society. According to the segmented assimilation theory and Bourdieu's theory of the habitus, I expect children of immigrants to assimilate in different segments of society by following distinct life trajectories that are not grounded in attending higher education because they do not have the necessary forms of knowledge to navigate the U.S. education system or the economic resources. Education still remains one of the most important and necessary tools for upward mobility, while access to higher education for children of immigrants across the United States becomes less promising. Measuring the level of education attained for individuals and their parents, income and occupational prestige, along with controlling for sex and race will further extend on the literature by contributing data from the 2016 General Social Survey. To measure the relationship between parents' birthplace and children educational attainment a bivariate analysis and a correlation 
matrix will be tested. Using the chi-square and the Pearson correlation value results will test the hypothesis that children of native U.S. born parents have a greater educational attainment than children of immigrants.

\section{METHODS}

I rely on the 2016 General Social Survey national dataset to examine the relationship between parents' place of birth and socioeconomic status and educational attainment: The unit of analysis is individuals, with a nationally representative sample size of 6,200 in the GSS with a 61.3 percent response rate (Smith et al. 2016). The valid cases used in this research paper contains 1,899 cases $(\mathrm{N}=1899)$. Missing cases were deleted from the data along with incomplete answers. To represent a cross-section of the country there was a random selection of households across the United States along with a randomly selected adult member of the household. The target population of the General Social Survey is adults (18+) living in households in the United States, English and/or Spanish speakers.

A total of 1,899 respondents were asked questions in regard to the independent, dependent, and control variables. For the independent variable - parents citizenship status — the question was stated as follows, were both your parents born in this country? $0=$ Both in U.S. 1=Mother only; $2=$ Father only; $3=$ Mother; $4=$ Not mother; $5=$ Father; $6=$ Not father; $7=$ Dk for both; $8=$ Neither in the U.S.; $-1=$ Not applicable; $9=$ no answer. The parents' birthplace variable was recoded from the original code: $0=$ Both in U.S, $1=$ Mother only, $2=$ Father only, $3=$ Mother, FA DK, 4=Not mother, FA DK, 5=Father; Mo.dk, 6=Not father; mo. dk, 7=dk for both, $8=$ neither in U.S, $9=$ NA recoded into $0=$ Both or at least one parent born in the U.S. and $1=$ Not born in the U.S. For the dependent variable, educational attainment, respondents were asked, 
what is the highest year of school completed? (respondents had the option of 0-20 year of education completed).

In order to measure socioeconomic status, I use the respondents' perceived family income at age sixteen and the mother and father's years of education completed. The perceived income question was asked as follows: Thinking about the time when you were 16 years old, compared with American families in general then, would you say your family income was-far below average, below average, average, above average, or far above average. In addition, respondents' mother and father were asked What is the highest year of school completed? (the option of 0-20 years of education was available for respondents).

Other control variables I analyze include race and sex. The race question asked: What race do you consider yourself? (the options resulted in $1=$ white, $2=$ black, and $3=$ other). The question for sex asked: What is the respondent's sex? $1=$ male, $2=$ female. I plan to operationalize perceived income, father and mother's education, race, and sex, in light of the question of how parents' birthplace relates to children of immigrants' educational attainment by analyzing univariate, bivariate, and multivariate regression analysis. For more information please visit the GSS website—http://gss.norc.org/—and precede to reference page for codebook and data links to website.

\section{FINDINGS}

Table 1 reports the means, medians, and standard deviations for all variables. According to Table 1, the mean for the independent variable, the birthplace of respondents' parents, was 14 percent meaning that 14 percent of the respondents parents were born outside of the United States. The average birthplace of respondents' parent is in the United States, the median was 0, and the standard deviation was .347. 
In Figure 1, the frequency distribution of this variable reveals that 86 percent of respondent's parents had both or at least one parent born in the U.S. and only 14 percent were not born in the U.S. (see page after references tables and figures).

**TABLE 1 ABOUT HERE**

**FIGURE 1 ABOUT HERE**

Table 1 also showed the univariate findings of the dependent variable—Educational attainment - with a mean of 14 , median of 14 , and standard deviation of 2.91 . As a result, the mean and median hold both the same value of 14 , which implies that the average years of school completed by the respondent is 14 years, which equates to a couple years beyond high school. A standard deviation of 2.91 shows that there is some variation in the dataset within the average years of school completed by respondents. In Figure 2, the frequency distribution of this measure revealed that on average about 64.5 percent of respondents completed about 13-20 years of school and 33 percent completed 9-12 years of school.

\section{**FIGURE 2 ABOUT HERE**}

In Table 1, for the control variable, respondents perceived family income at 16 years old control variable, Table 1 disclosed that the mean was 2.9 , meaning that the average individual perceived their family income to be in close to average to below average. The median was 3.00 and the standard deviation was .909 , meaning that compared to the mean of 2.9 there is a small amount of variance across respondents' perceived family income. In Figure 3, the majority of respondents (44 percent) perceived their family income to be average, whereas about roughly the same number of respondents believed their perceived family income to be below average ( 24 percent) and above average ( 23 percent). Only about 7.5 percent perceived their family income 
to be far below average and only 2 percent perceived it to be far above average. Figure 3 holds a normal distribution.

\section{**FIGURE 3 ABOUT HERE**}

For father and mother educational attainment, the mean, median, and standard deviation were relatively close in numbers in Table 1. For mother's educational attainment the mean was 12.00, the median was 12.00 and the standard deviation was 3.634. With a standard deviation of 3.634 there is more variance which could indicate that some mothers could be on either side of the spectrum on the amount of years of education achieved. Similarly, respondents' father educational attainment mean was 11.90 , the median was 12 , and the standard deviation was 3.993 which is a little higher than the mothers' educational attainment standard deviation. In Figure 4, 50 percent of the respondents' mother completed at least 9-12 years of education and 33 percent of mothers completed 13-20 years of education and only .5 percent completed 0-5 years of school. In Figure 5, similar to that of the mother's educational attainment frequency distribution, 47 percent of fathers completed about 9-12 years of education 34 percent completed 13-20 years and 7 percent completed 0-5 years of education.

\section{**FIGURE 4 ABOUT HERE** \\ **FIGURE 5 ABOUT HERE**}

When comparing the means, median, and standard deviation for race and sex in Table 1, it was revealed that the mean for race was .12 and the median was 0 , with a standard deviation of .327 meaning that the average respondent was white and that there was little to no variance. For sex, the mean was .55 and the median was 1.0 , with a standard deviation of .497 . Keeping in mind that race and sex were recoded variables as follow, $0=$ white and $1=$ black and $0=$ men and 1=women. In Figure 6, the frequency distribution of this measure skewed to the left, indicating 
that the majority of respondents considered themselves to be white and/or other ( 88 percent) and a small percentage of 12 percent of respondents considered themselves to be black. In Figure 7 , the frequency distribution of this measure showed that 55 percent of the respondents classified as female and 45 percent of the sample were men.

**FIGURE 6 ABOUT HERE**

**FIGURE 7 ABOUT HERE**

At the bivariate level, all statistically significant correlations between two given variables were significant at the $p<.01$ level. The results showed a very weak negative relationship between parents not born in the U.S. and respondents' highest year of school completed ( $r=$ .079). There was a significant weak positive relationship between respondents' perceived family income at 16 years old and the highest year of school completed. There was a moderate positive statistically significant relationship between highest year of school completed for father and mother and respondents' highest year of school completed (see Table 2). The correlation coefficients were positive, indicating that increases in father $\left(r=.421^{* *}\right)$ and mother $\left(r=.397^{* *}\right)$ years of schooling were linked to increases in respondents' years of schooling. There was a statistically significant relationship between respondents' highest year school completed and the respondents perceived family income at age 16, father's and mother's highest year of schooling completed, and being black. In addition, there was a statistically significant relationship between parents who were not born in the United States and the respondents perceived family income at age 16, father's and mother's highest year of schooling completed. There was no statistically significant relationship between parents born in the United States and the respondent being a black female. In addition, there is a weak negative relationship between respondents' perceived income at 16 years old and parents born in the U.S. There is also a weak negative statistically 
significant relationship between father's highest year of school completed and respondents' perceived income at age $16\left(r=-.380^{* *}\right)$. Meaning that as the years of schooling decreased the less respondents perceived to have an income above average.

There is a positive moderate relationship between mothers' highest year of school completed and respondents' perceived family income at age $16\left(r=.359^{* *}\right)$. As the percentage of school years increased the family perceived income at age 16 increased. There is a very weak negative relationship between being black and perceived income at age 16 . There is a very weak negative relationship between being a female and perceived family income at age $16\left(r=-.046^{*}\right)$. There is no statistically significant relationship between being a black female and father's years of schooling completed. In addition, there is a very strong positive statistically significant relationship between the amount of years of schooling completed by the father and mother.

\section{** TABLE 2 ABOUT HERE**}

The bivariate analysis results show that the independent variable is intercorrelated with, respondents perceived income at age 16 and parent's educational attainment. In order to get a clear picture of the real driving force of educational attainment I created a three-model regression analysis to see how each individual variable affected the dependent variable. All else being equal, the regression equation result shows that after running a three-model multivariate regression it was found that $\mathrm{R}^{2}$ in the first model is .006 which means that 0.6 percent of the variation in educational attainment can be explained by parent's birthplace. Controlling for other factors, after adding the variables sex and race in model two, it explains 1.00 percent of respondents' educational attainment. Finally, in model three after adding mother and father's highest year of school completed and respondent's family income at age 16 explains 20 percent of the variation in respondent's educational attainment can be explained by all of these variables 
together. The $\mathrm{R}^{2}$ increases dramatically from the first model (1 percent) to the third model (20 percent). All three models are statistically significant according to the f-test equation which means that the equation is different than the y-intercept equation $(p<.01)$. Parents' highest year of school completed has the largest effect on respondents' educational attainment.

In the first model, the coefficient for the parent's birthplace is statistically significant $(p<.01)$, the -.665 means that if respondents' parents were not born in the United States you only complete two thirds of a year less of education. In model 2, after controlling for race and sex parent's birthplace remains statistically significant $(p<.01)$. However, in model 3, after adding parents' educational attainment the parents' birthplace coefficient decreases and becomes insignificant. For each additional year of mother's education, the respondent has .172 more years. In addition, in model 3, fathers' educational attainment is statistically significant $(p<.01)$ which implies that for each additional year of schooling the father has the respondent has .193 more years of schooling.

** TABLE 3 ABOUT HERE** 


\section{DISCUSSION}

While the parent's birthplace bears an effect on the respondents' educational attainment, parents' educational attainment has a greater effect than the other control variables. The control variables may not clearly nor completely offer explanations to why immigrant children are less likely to attain a higher education, but the variables do show the relationship between socioeconomic status and respondents' educational attainment. The data analysis confirms that there is a potentially spurious or mediated relationship between the independent variable, parents' birthplace, and the dependent variable, educational attainment. This suggest that respondents' whose parents were not born in the U.S. have less education.

However, that is not the case when the control variables are added, it is visibly clear as the $\mathrm{R}^{2}$ increases across the models that this relationship is mediated by parents' educational attainment. The hypothesis is partially supported at the bivariate level it does appear to be the case the parents' birthplace has an effect on respondents' educational attainment. Yet, at the multivariate level it appears that this relationship is driven by other factors. The real driver of educational attainment in this study is parents' educational attainment. Surprisingly, all else being equal, the location of child's birthplace is not as important as education.

Which implies that there is a global cosmopolitanism, where being a citizen of the world presumes human connectedness and the development of ethical relationships. Meaning that no matter where one is born being a citizen of a community entails that individuals are morally and culturally socialized in very similar ways.

Similarly, a crucial component of Bourdieu's habitus theory is the social and cultural capital acquired through integration. Since social and cultural attainment is determined by accessibility - financial status, environment, exposure to cultural capital—one would predict 
that parents born in the United States have more resources to offer their children who have acquired greater habitus to navigate the education system and social spaces, thus, increasing their access to a higher educational attainment. However, the data analysis implies that despite parents' birthplace the habitus of social and cultural capital can be attained by being nurtured by an educated parent(s). This idea can lead us to the conclusion that educated parents have an unspoken habitus across origins. If a parent is educated, no matter where they are from, their kids are more likely to be equipped to pursue a higher education.

Furthermore, recalling the previous studies and prior empirical research on straight line assimilation holds that there is a presumed path immigrant child should follow which will ultimately lead students to becoming more similar over time in norms, values, behaviors, and characteristics. On the other hand, the segmented assimilation theory outlines several distinct trajectories that children of immigrants follow. As expected, individual pathways are very different across cases but, having educated parents can reduce the probability of downward mobility. When parents are highly educated the straight-line assimilation, theory does not hold because it doesn't matter where they are from the learned values and behaviors allow children of immigrants to progress in education while retaining the foundations of their culture. Yet, by and large, educated immigrants are in a much better competitive position and more likely to succeed occupationally and economically in their new environment. Immigrants fortunate enough to join more advantaged ethnic communities can translate their education and occupational skills into economic returns, even when still confronted with the barrier of new language and culture.

\section{CONCLUSION}

To summarize my findings, I have to first recall Bourdieu's notions of habitus and cultural capital. It remains crucial for understanding how social class shapes individuals and their 
future pathways to a higher education; empirical studies find an overall positive association between socioeconomic status and parental involvement (Cherng and Ho 2018). Bourdieu habitus theory is a critical component for this study as it pertains to the explanation of how individuals acquire their behaviors, taste, and aspirations. The allocation of resources and economic capital is part of the habitus as it determines what kind of exposure different groups of people are able to navigate (1990). The question explored in this paper was, how does socioeconomic status shape postsecondary/higher education pathways among the children of immigrants and non-immigrants? The iterative regression analysis shows that socioeconomic status can possibly be determined by parents' educational attainment which leads to the kind of occupation one has available to them. On average respondents had about 12-14 years of education. The more years of education one has the more prepared they are for the job market and the more cultural and social capital they are able to gain. These gains can easily be transmitted to their children.

The results support theorists like Alba and Nee (1997), and Bourdieu (1990). It shows that education is still a prevalent factor to gain upward mobility and education is a positive route for assimilation. These theorists suggest that there should be more resources available to children of immigrants whose parents have little to no education. For example, funding more academic coaches and mentors who can prepare children of immigrants for higher education.

\section{Limitations}

While this study is the first that examines the relationship between parent's birthplace and educational attainment by using the 2016 GSS, it still has some limitations. First, the income variable is flawed because it only asks the individuals about their perceived income at age 16 which could be misconstrued by the respondents due to the fact that at age of 16 parents might 
not share their financial situation with their children. Also, the long period of time from when the question was asked could have been misinterpreted and is not reliable. The variables themselves may not have clearly nor completely offered explanations for educational attainment. For example, the educational attainment variable did not discern whether they accounted for degrees obtained online or other less traditional institutions like vocational, technical, or home schools. In addition, socioeconomic status was measured in regard to occupational prestige, income, and education and this alone does not measure cultural capital. Cultural capital is considered to be composed of a plethora of experiences that yield different forms of knowledge from a community. Cultural capital can be measured by what kind of religious group one is associated, food, music, and more. Future researchers should control for, family structure, student aspirations, cultural capital, and parent's optimism of children excelling in school. Another limitation is that this study was not longitudinal as it only analyzed data from one year in the GSS. A cross-sectional study might not be able to capture the long-term patterns of immigrant children and their pathways to educational attainment.

Future research should focus on obtaining ethnographic data to fully understand the individuals struggles and different pathway models to educational attainment. In many cases, there are multiple factors that contribute to student's educational attainment more specifically, language, environment, learning disability, immigrant status, and intersectionality of identities. Nonetheless, immigrants are a part of our communities and as they become integrated in our lives their wellbeing matters, if they are not able to attend a higher education or participate in the community as educated individuals the will not be able to engage in the democratic process, the economic system, or have access to upward mobility. The findings in this study allude to the global cosmopolitanism concept which suggests that being a citizen of the world presumes humans are interconnected. Regardless of where parents are born education is one of the key 
factors as to why some children attain a higher education than most which leads to the conclusion that across national lines, educated individuals have some sort of unspoken cultural and social capital that we all share. 


\section{References}

Alba, R., \& Nee, V. (1997). Rethinking Assimilation Theory for a New Era of Immigration. The InternationalMigration Review,31(4), 826-874.

Alon, Sigal. 2009. "The Evolution of Class Inequality in Higher Education: Competition, Exclusion, and Adaptation." American Sociological Review 74(5):731-755

Bautista, Rene \& Smith, Tom. 2016. General Social Surveys.1972-2016 Cumulative Codebook and Data file. Chicago, IL: National Opinion Research

Benner, Aprile, Alaina Boyle and Sydney Sadler. 2016. "Parental Involvement and Adolescents' Educational Success: The Roles of Prior Achievement and Socioeconomic Status." Journal of Youth \& Adolescence 45(6):1053-1064

Bourdieu P. 1990. Structures, habitus, practices. In The Logic of Practice

Benner, Aprile, Alaina Boyle and Sydney Sadler. 2016. "Parental Involvement and Adolescents' Educational Success: The Roles of Prior Achievement and Socioeconomic Status." Journal of Youth \& Adolescence 45(6):1053-1064

Byun, Soo-yong, and Hyunjoon Park. 2012. "The Academic Success of East Asian American Youth: The Role of Shadow Education." Sociology of Education 85(1):40-60

Cipollone, Kristin, and Amy E. Stich. 2017. "Shadow Capital: The Democratization of College Preparatory Education." Sociology of Education 90(4):333-354

Cherng, Hua-Yu S., and Phoebe Ho. 2018. "In Thoughts, Words, and Deeds: Are Social Class Differences in Parental Support Similar Across Immigrant and Native Families?" Sociological Quarterly59(1):85-110 
Cox, Amanda B. 2017. "Cohorts, "Siblings," and Mentors: Organizational Structures and the Creation of Social Capital." Sociology of Education 90(1):47-63

Dumais, Susan A. 2006. "Early Childhood Cultural Capital, Parental Habitus, and Teachers' Perceptions." Poetics 34(2):83-107

Feliciano, Cynthia. 2005. "Does Selective Migration Matter? Explaining Ethnic Disparities in Educational Attainment among Immigrants' Children." The International Migration Review 39(4):841-871

Feliciano, Cynthia, and Yader R. Lanuza. 2017. "An Immigrant Paradox? Contextual Attainment and Intergenerational Educational Mobility." American Sociological Review 82(1):211-241

Gonzales, Roberto G. 2011. "Learning to be Illegal: Undocumented Youth and Shifting Legal Contexts in the Transition to Adulthood."American Sociological Review 76(4):602-619

López Gustavo, Bialik Kristen and Radford Jynnah. 2018. "Key Findings about U.S. Immigrants.", Retrieved 12/10/2018. (http://www.pewresearch.org/fact-tank/2018/11/30/keyfindings-about-u-s-immigrants/).

Hirschman, Charles. 2016. From High School to College: Gender, Immigrant Generation, and Race-Ethnicity. New York: Russell Sage Foundation Press.

Hsin, Amy, and Francesc Ortega. 2018. "The Effects of Deferred Action for Childhood Arrivals on the Educational Outcomes of Undocumented Students." Demography 55(4):14871506

Lareau, Annette. 2002. "Invisible Inequality: Social Class and Childrearing in Black Families and White Families." American Sociological Review 67(5):747-776 
Torche, Florencia. 2011. "Is a College Degree Still the Great Equalizer? Intergenerational Mobility Across Levels of Schooling in the United States." American Journal of Sociology 117(3):763-807

Par Robert. E \& Burgess. Ernest W. (1969) Introduction to the Science of Sociology. Reprint 1921. Chicago: University of Chicago Press

Qian, Yue, Claudia Buchmann and Zhe Zhang. 2018. "Gender Differences in Educational Adaptation of Immigrant-Origin Youth in the United States." Demographic Research 38:11551188

Raleigh, Elizabeth, and Grace, Kao. 2010. "Do Immigrant Minority Parents have More Consistent College Aspirations for their Children?" Social Science Quarterly 91(4):1083-1102

Smith, Tom W., Peter Marsden, Michael Hout, and Jibum Kim. General Social Surveys, 2016.Principal Investigator, Tom W. Smith; Co-Principal Investigator, Peter V. Marsden; CoPrincipal Investigator, Michael Hout; Sponsored by National Science Foundation. -NORC ed.Chicago: NORC at the University of Chicago [producer and distributor]. Data accessed from the GSS Data Explorer website at gssdataexplorer.norc.org.

Zanin, Luca. 2017. "Education and Life Satisfaction in Relation to the Probability of Social Trust: A Conceptual Framework and Empirical Analysis." Social Indicators Research 132(2):925-947 
Table 1. Means, Medians, and Standard Deviation for Variable $(\mathrm{N}=1899)$

\begin{tabular}{lccc}
\hline \hline Variable & Mean & Median & SD \\
\hline Parents Birthplace & 1.40 & .00 & .35 \\
Educational Attainment & 14.20 & 14.00 & 2.91 \\
Mother Educational Attainment & 11.97 & 12.00 & 3.63 \\
Father Educational Attainment & 11.90 & 12.00 & 3.99 \\
Perceived Income at age 16 & 2.88 & 3.00 & .91 \\
Respondent Race & 1.22 & .00 & .33 \\
Respondent Sex & & & .50 \\
\hline
\end{tabular}

Table 2. Correlation Matrix $(n=1899)$

\begin{tabular}{|c|c|c|c|c|c|c|}
\hline & $\begin{array}{l}\text { Parents Not } \\
\text { Born in the } \\
\text { U.S. }\end{array}$ & $\begin{array}{c}\text { Respondents } \\
\text { Family } \\
\text { Income at } \\
16 \text { years old }\end{array}$ & $\begin{array}{l}\text { Highest year } \\
\text { of school } \\
\text { completed } \\
\text { father }\end{array}$ & $\begin{array}{l}\text { Highest year } \\
\text { of school } \\
\text { completed, } \\
\text { mother }\end{array}$ & Black & Women \\
\hline $\begin{array}{l}\text { Highest year of school } \\
\text { completed for respondents }\end{array}$ & $-.079 * *$ & $.226 *$ & $.421 * *$ & $.397 * *$ & $-.060 * *$ & .020 \\
\hline New Parents Birthplace & & $-.126 * *$ & $-.215^{* *}$ & $-.302 * *$ & .003 & .008 \\
\hline $\begin{array}{l}\text { Respondents Family Income } \\
16 \text { years old }\end{array}$ & & & $.380 * *$ & $.359 * *$ & $-.091 * *$ & $-.046^{*}$ \\
\hline $\begin{array}{l}\text { Highest year of school } \\
\text { completed father }\end{array}$ & & & & $.683^{* *}$ & -.036 & -.034 \\
\hline $\begin{array}{l}\text { Highest year of school } \\
\text { completed, mother }\end{array}$ & & & & & -.010 & $-.066 * *$ \\
\hline
\end{tabular}


Table 3. Three-Model Regression of Parents place of birth on All Variables

\begin{tabular}{lccc} 
Variable & Model 1 & Model 2 & Model 3 \\
\hline $\begin{array}{c}\text { Parents Not Born in } \\
\text { the U. S } \\
\text { Black }\end{array}$ & $-.665^{* *}$ & $-.665^{* *}$ & .410 \\
Women & -- & -.536 & -.396 \\
& -- & .129 & .272 \\
Mother's Highest year \\
$\begin{array}{l}\text { of school completed } \\
\begin{array}{l}\text { Father's Highest year } \\
\text { of school completed }\end{array}\end{array}$ \\
$\begin{array}{l}\text { Respondents family } \\
\text { income at age } 16\end{array}$ & -- & -- & $.172^{* *}$ \\
Constant & -- & -- & $.193^{* *}$ \\
\hline $\begin{array}{l}R^{2} \\
F\end{array}$ & 14.296 & -- & .168 \\
\hline
\end{tabular}

$*^{*} p<.01 ;$ Unstandardized coefficients

$n=1899$

\section{Parents' place of birth}

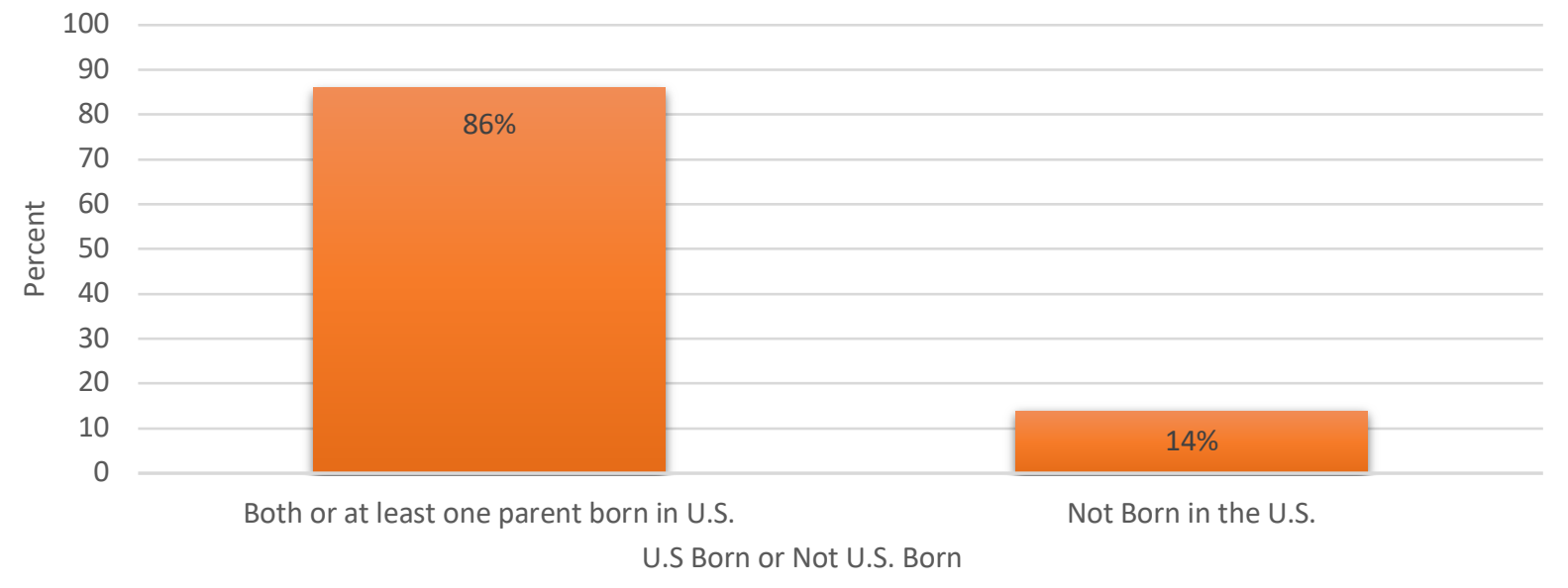

Figure 1. Bar graph of parents' birth place percentage. 


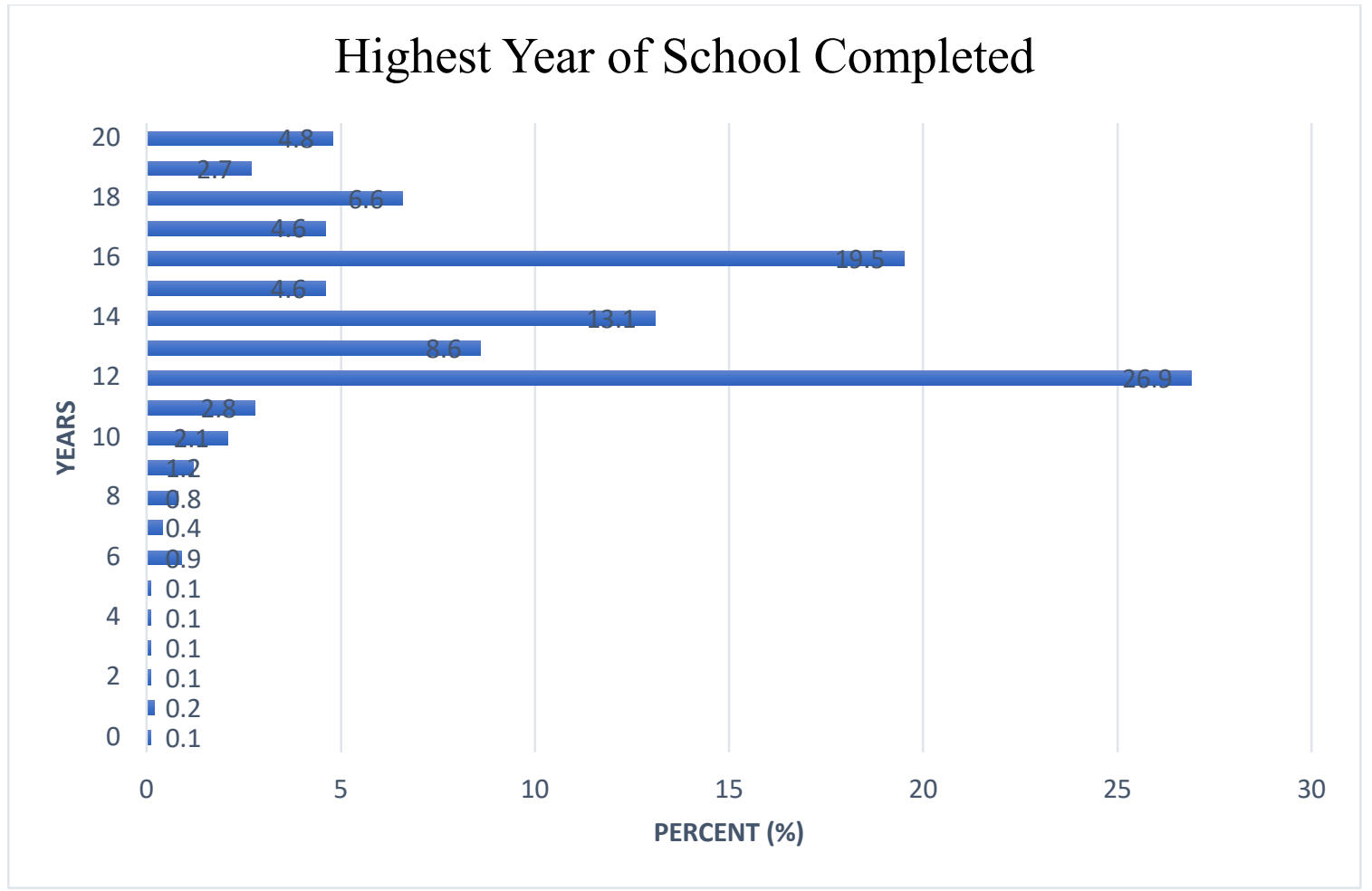

Figure 2. Clustered bar of respondents' Highest year of school completed.

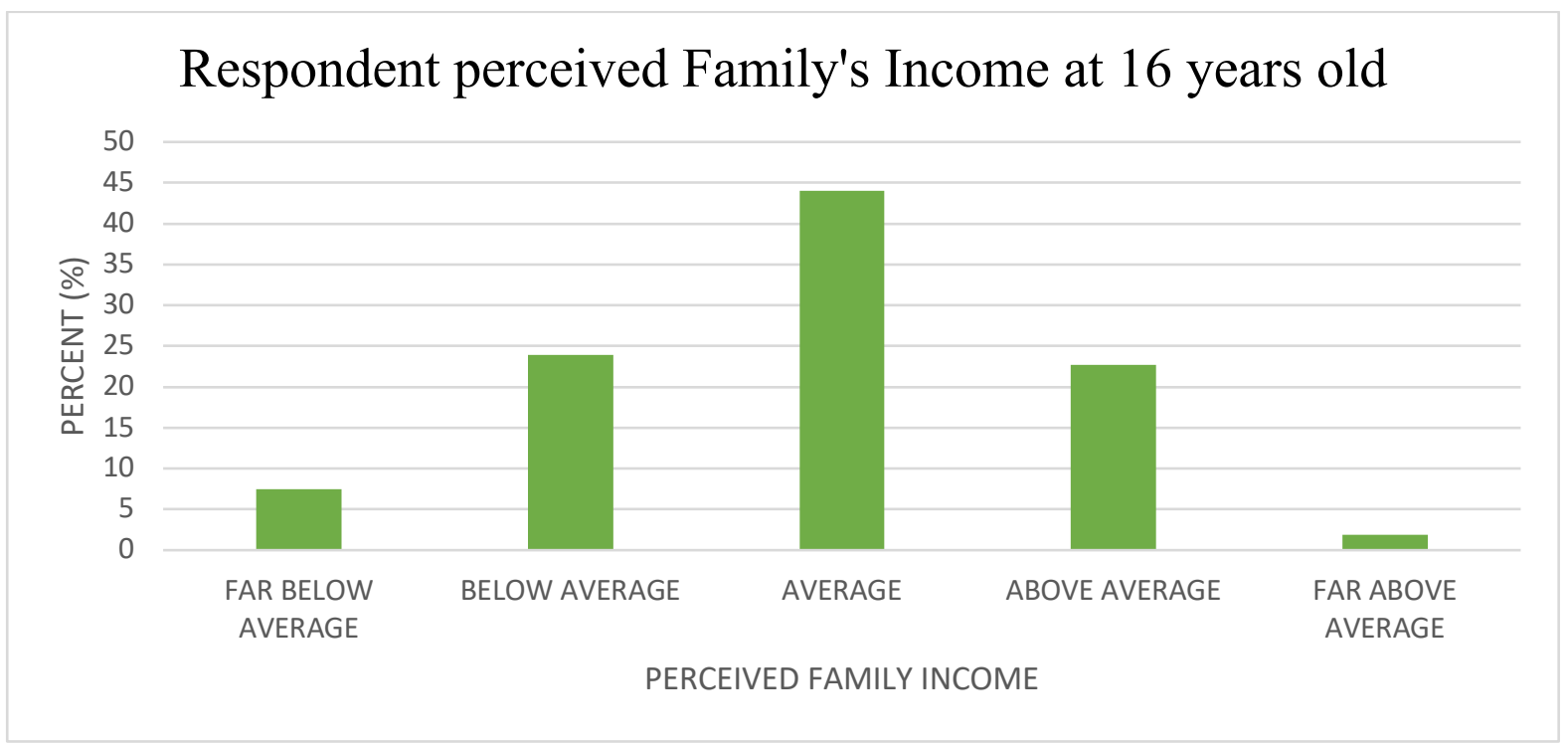

Figure 3. Histogram of respondents' perceived family's Income at age 16. 


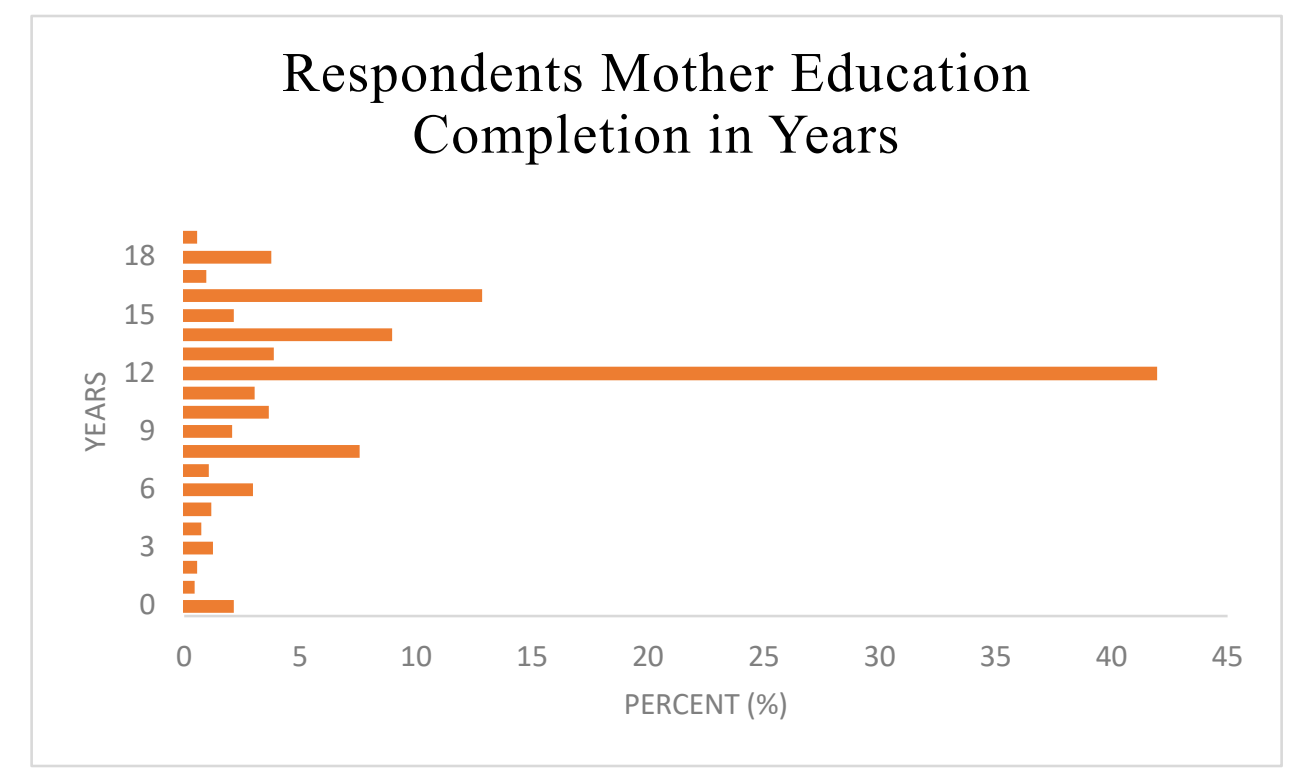

Figure 4. Clustered column graph Respondents' Mother Education Completion in Years

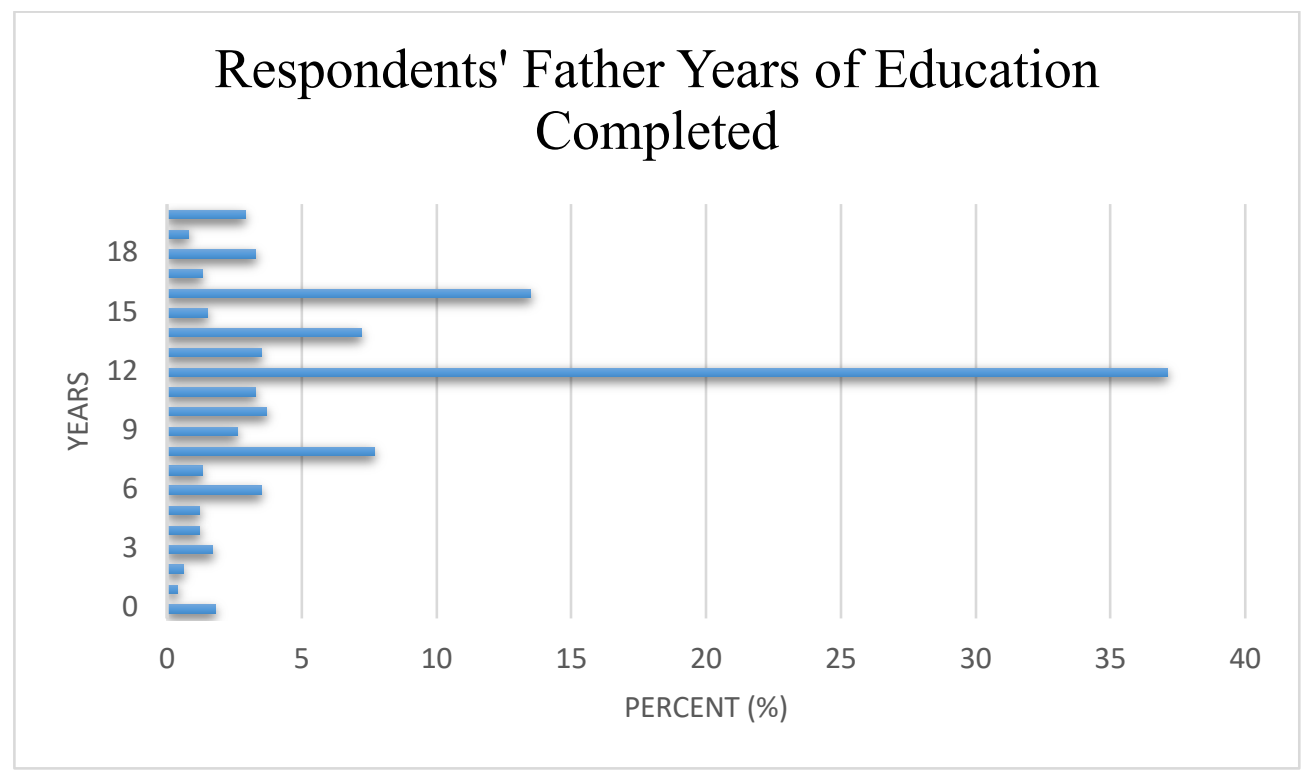

Figure 5. Clustered column graph Respondents' Father Education Completion in Years 


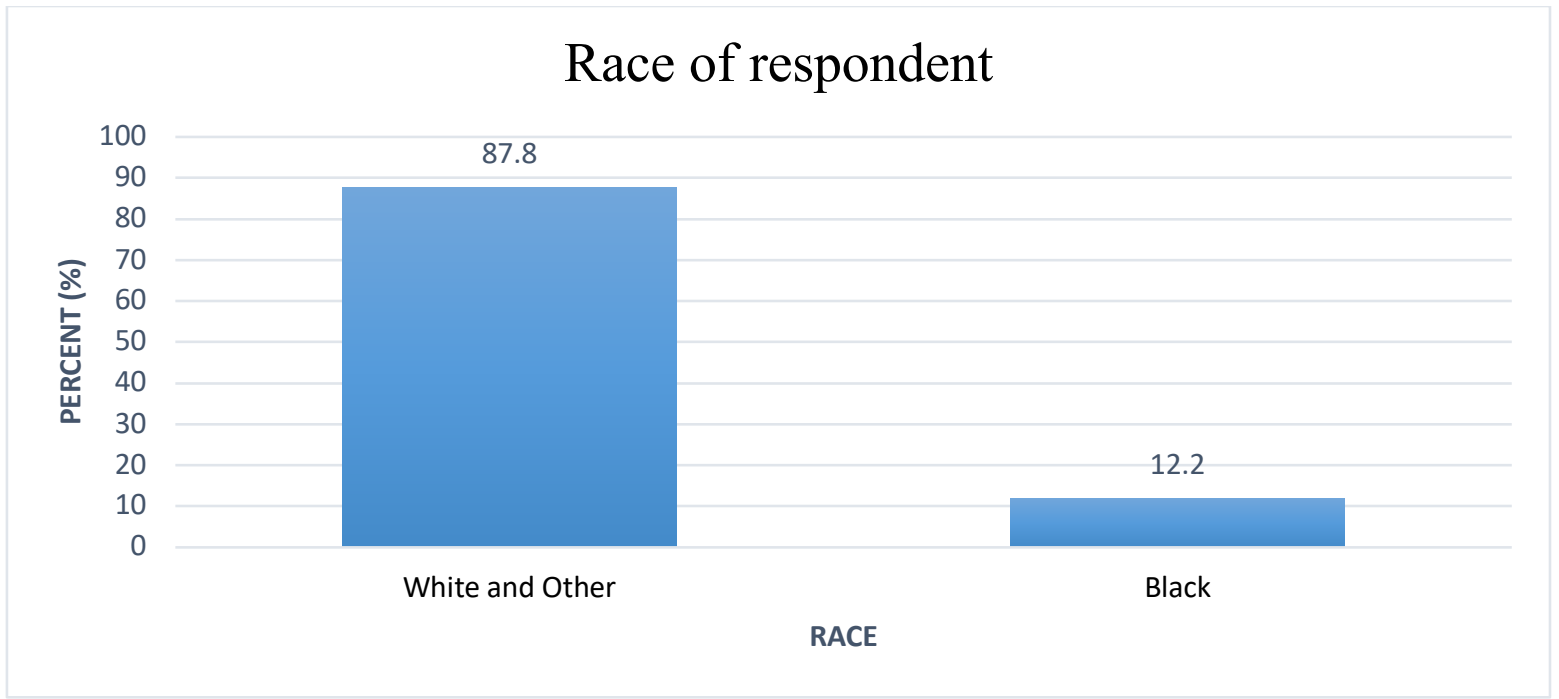

Figure 6. Histogram of respondents' Race.

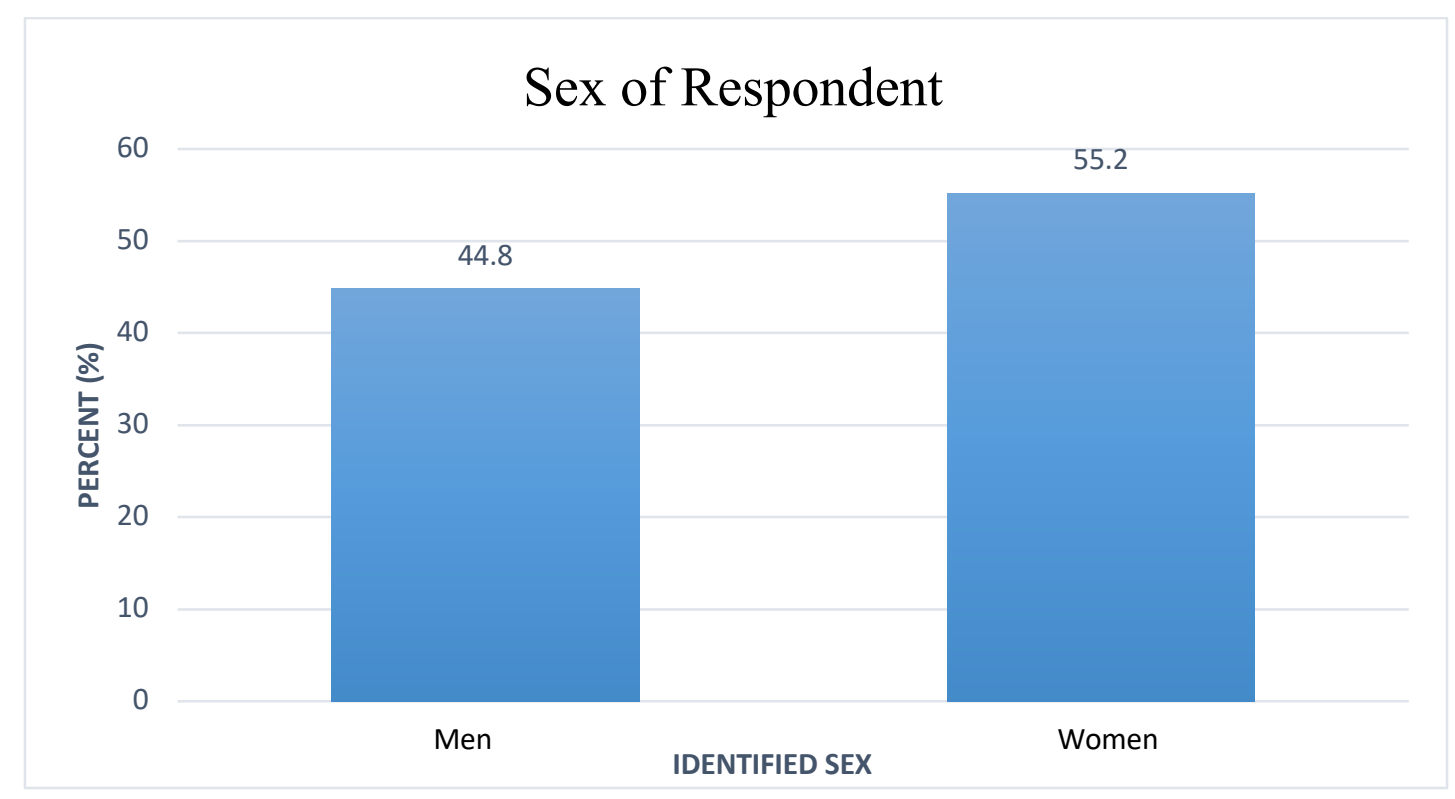

Figure 7. Histogram of respondents' Sex. 